\title{
Factors associated with poor discharge status in patients with status epilepticus at Khon Kaen Hospital
}

\author{
Piyawan Chiewthanakul' \\ Parinya Noppaklao ${ }^{2}$ \\ Kittisak Sawanyawisuth ${ }^{3,4}$ \\ Somsak Tiamkao 3,5 \\ 'Department of Medicine, Khon \\ Kaen Hospital, Khon Kaen, Thailand; \\ ${ }^{2}$ Department of Medicine, Faculty \\ of Medicine, Khon Kaen University, \\ Khon Kaen, Thailand; ${ }^{3}$ Department \\ of Medicine, Faculty of Medicine, \\ Khon Kaen University, Khon Kaen, \\ Thailand; ${ }^{4}$ Research Center in Back, \\ Neck, Other Joint Pain and Human \\ Performance (BNOJPH), Khon Kaen \\ University, Khon Kaen, Thailand; \\ ${ }^{5}$ Integrated Epilepsy Research Group, \\ Khon Kaen University, Khon Kaen, \\ Thailand
}

This article was published in the following Dove Press journal:

Neuropsychiatric Disease and Treatment

20 April 2015

Number of times this article has been viewed

Background: Status epilepticus (SE) is a serious neurological condition and has high a mortality rate. Data on importance of factors associated with poor outcomes in Asian or Thai populations are limited.

Methods: Adult patients diagnosed as SE at Khon Kaen Hospital, Thailand from October 1, 2010 to September 30, 2012 were enrolled. Patients were categorized as good or poor outcomes at discharge. Good outcomes were defined by improvement at discharge and absence of neurological deficits, while poor outcomes were defined by: not being improved at discharge; being discharged against advice; death; or presence of a neurological deficit. Clinical factors were compared between both groups.

Results: During the study period, there were 211 patients diagnosed as SE. Of those, 130 patients were male (61.61\%). The mean age of all patients was 53.28 years. Acute stroke was the most common cause of SE in 33 patients (15.64\%). At discharge, there were 91 patients $(43.13 \%)$ who had poor outcomes. Only initial plasma glucose levels were significantly associated with poor outcomes with an adjusted odds ratio of 1.012 (95\% confidence interval of 1.003 and 1.021).

Conclusion: Initial plasma glucose is associated with poor discharge status in patients with SE.

Keywords: hyperglycemia, outcomes, prognosis, risk factors

\section{Introduction}

Status epilepticus (SE) is an emergency neurological condition defined as a continuous seizure of more than 5 minutes. ${ }^{1}$ Its prevalence varies between 10 and 41 cases per 100,000 population outside of Thailand. ${ }^{2}$ In Thailand, SE occurred in 5.10 cases per 100,000 population with a mortality rate of 0.6 per 100,000 population. ${ }^{3}$ Causes of SE are different between countries. A report from Taiwan showed that central nervous system infection and previous strokes are the two most common causes of SE, ${ }^{4}$ while antiepileptic drug (AED) withdrawal and alcohol-related causes were leading causes of SE in Western countries. ${ }^{5}$

Factors associated with poor outcomes of SE were related to comorbid complications such as metabolic disorders, cerebrovascular disease, and hypoxemia as shown in systematic reviews. ${ }^{6,7}$ A report from Thailand did not find any significant predictors for SE. ${ }^{2}$ Unlike in Western countries, there are limited data on predictors of SE outcomes in Thailand and other Asian countries. Here, the study was aimed to determine whether any factors associated with initial laboratory findings or treatment of SE had influences on outcomes at discharge.

Correspondence: Somsak Tiamkao Department of Medicine, Faculty of Medicine, Khon Kaen University, 123 Mittraphap Road, Khon Kaen 40002, Thailand

Tel +66 43363664

Fax +6643348399

Email somtia@kku.ac.th 


\section{Materials and methods}

This study retrospectively reviewed charts of adult patients who were at least 15 years old and diagnosed as SE at Khon Kaen Hospital from October 1, 2010 to September 30, 2012. SE patients were identified by using the International Classification of Diseases code G41. Khon Kaen Hospital is the tertiary care hospital located in the northeastern part of Thailand.

Baseline characteristics, initial laboratory findings, treatment, and treatment outcomes were recorded. Patients were categorized into two groups by type of discharge status and neurological outcomes; good or poor outcomes. Good outcomes were defined by improvement at discharge and absence of neurological deficits, while poor outcomes were defined by: not being improved at discharge; being discharged against advice; death; or presence of a neurological deficit.

\section{Statistical analysis}

Descriptive statistics were used to detect significant differences between patients with good and poor outcomes. Univariate logistic regression analysis was applied to calculate the crude odds ratios (ORs) of individual variables for having poor outcomes. All variables with $P<0.20$ in univariate analysis were included in subsequent multivariate logistic regression analysis. The final model was composed of factors associated with poor outcomes. Analytical results are presented as adjusted ORs, and 95\% confidence intervals.

The study protocol was approved by an institutional review committee, Khon Kaen University (HE 561217).

\section{Results}

During the study period, there were 211 patients diagnosed as SE. Of those, 130 patients were male (61.61\%). The mean age (standard deviation [SD]) of all patients was 53.28 years (15.92). Epilepsy (24.64\%) and hypertension (23.22\%) were the two most common comorbid diseases. Generalized tonic-clonic seizure was the most common type of SE (179 patients; 94.71\%). Acute stroke was the most common cause of SE in 33 patients (15.64\%). Other common causes of SE are shown in Table 1. The mean (SD) numbers of AEDs used were 2.05 (1.56) and the mean (SD) length of stay was 5.12 days (6.75). There were 104 patients (49.29\%) who developed complications after SE and the most common complication was aspiration pneumonia (53 patients; $25.12 \%)$.

At discharge, there were 120 patients $(56.87 \%)$ who had good outcomes, while 91 patients $(43.13 \%)$ had poor
Table I Causes of status epilepticus in the present study

\begin{tabular}{ll}
\hline Causes & Number (\%) \\
\hline Acute stroke & $33(15.64)$ \\
Alcohol related (withdrawal/toxicity) & $30(14.22)$ \\
Sepsis & $24(I 1.37)$ \\
Central nervous system infection & $19(9.00)$ \\
AED withdrawal & $19(9.00)$ \\
Cardiac arrest & $18(8.53)$ \\
Post-stroke & 1 I $(5.21)$ \\
Subtherapeutic AED level & $11(5.21)$ \\
Hyponatremia & $7(3.32)$ \\
Hyper-/hypoglycemia & $5(2.37)$ \\
Acute subdural hematoma & $4(1.90)$ \\
Uremia & $4(1.90)$ \\
Acute febrile illness & $4(1.90)$ \\
Hypertensive encephalopathy & $4(1.90)$ \\
Sleep deprivation & $4(1.90)$ \\
Venous sinus thrombosis & $3(1.42)$ \\
Others & $11(5.21)$ \\
\hline
\end{tabular}

Notes: "Others" were autoimmune encephalitis, brain abscess, hydrocephalus, central nervous system vasculitis, hypocalcemia, intracerebral hemorrhage, posterior reversible encephalopathy syndrome, subarachnoid hemorrhage, and subdural hygroma.

Abbreviation: AED, antiepileptic drug.

outcomes categorized by: death (29 patients; $13.74 \%$ ); not improved or discharged against advice (55 patients; $26.07 \%$ ); and presence of neurological deficits (7 patients; $3.32 \%)$. Most clinical factors at initial presentation were comparable between those who had good and poor outcomes at discharge (Tables 2 and 3). Those who had poor outcomes had more SE occurrences in hospital $(30.77 \%$ versus $3.33 \%$ ), a lower Glasgow coma scale (7.97 versus 9.78), higher plasma glucose (203.11 versus $159.26 \mathrm{mg} / \mathrm{dL}$ ), lower serum albumin ( 2.73 versus $3.52 \mathrm{~g} / \mathrm{dL}$ ), higher serum aspartate aminotransferase (171.36 versus $82.78 \mathrm{U} / \mathrm{L}$ ), and higher total bilirubin (1.84 versus $1.04 \mathrm{mg} / \mathrm{dL}$ ) than those with good outcomes. The serum electrolytes, except for potassium and phosphate levels, were also statistically different between those who had good and poor outcomes (Table 3). In the final model of multivariate analysis, only plasma glucose was significantly associated with poor outcomes with an adjusted OR of 1.012 (95\% confidence interval of 1.003 and 1.021).

Regarding treatment and treatment outcomes, those with poor outcomes had a higher proportion of recurrent SE $(42.86 \%$ versus $10.83 \%)$ and longer duration of respirator use (4.18 versus 1.83 days) as shown in Table 4.

\section{Discussion}

This study showed two important findings: poor discharge status of SE in a tertiary care hospital was $43.13 \%$ and the discharge status of SE patients was associated with initial 
Table 2 Clinical factors at initial presentation of patients with SE categorized by type of hospital discharge

\begin{tabular}{|c|c|c|c|}
\hline \multirow[t]{2}{*}{ Factors } & \multirow{2}{*}{$\begin{array}{l}\text { Good outcome } \\
N=120\end{array}$} & \multirow{2}{*}{$\begin{array}{l}\text { Poor outcome } \\
N=9 \text { I }\end{array}$} & \multirow[t]{2}{*}{$P$-value } \\
\hline & & & \\
\hline Male & $76(63.33)$ & $54(59.39)$ & 0.555 \\
\hline Mean age (SD), years & $52.7 \mid(\mid 8.7 I)$ & $54.04(19.58)$ & 0.655 \\
\hline \multicolumn{4}{|l|}{ Comorbid diseases } \\
\hline Hypertension & $28(23.33)$ & $21(23.08)$ & 0.965 \\
\hline Diabetes mellitus & $23(19.17)$ & $16(17.58)$ & 0.769 \\
\hline Alcoholism & $13(10.83)$ & 7 (7.69) & 0.445 \\
\hline Stroke & $27(22.50)$ & $20(21.98)$ & 0.928 \\
\hline Epilepsy & $31(25.83)$ & $21(23.08)$ & 0.645 \\
\hline \multicolumn{4}{|l|}{ Causes of SE } \\
\hline Acute stroke & $22(18.33)$ & II (I2.09) & 0.432 \\
\hline AED withdrawal & $9(7.50)$ & $10(10.99)$ & $0.38 \mathrm{I}$ \\
\hline Alcohol related & $14(11.67)$ & $16(17.58)$ & 0.223 \\
\hline Cardiac arrest & $11(9.17)$ & $7(7.68)$ & 0.704 \\
\hline CNS infection & $7(5.83)$ & $12(13.19)$ & 0.065 \\
\hline Septic encephalopathy & $12(10.00)$ & $12(13.19)$ & 0.470 \\
\hline \multicolumn{4}{|l|}{ Type of SE } \\
\hline Generalized tonic-clonic & $103(95.37)$ & $76(93.83)$ & 0.703 \\
\hline Nonconvulsive & $\mathrm{I}(0.93)$ & $2(2.47)$ & 0.703 \\
\hline Epilepsia partialis continua & $4(3.70)$ & $3(3.70)$ & 0.703 \\
\hline \multicolumn{4}{|l|}{ Place of SE occurrence } \\
\hline Home & $106(88.33)$ & $55(60.44)$ & $<0.001$ \\
\hline Primary Hospital & $10(8.33)$ & $8(8.79)$ & $<0.001$ \\
\hline Khon Kaen hospital & $4(3.33)$ & $28(30.77)$ & $<0.001$ \\
\hline History of previous SE & $10(8.33)$ & $2(2.20)$ & 0.057 \\
\hline
\end{tabular}

Notes: Poor outcome: discharge by death, not improved, or discharged against advice. Khon Kaen Hospital is a tertiary care hospital. Data presented as number (percentage) unless indicated.

Abbreviations: AED, antiepileptic drug; CNS, central nervous system; SD, standard deviation; SE, status epilepticus.

Table 3 Physical signs and laboratory findings at initial presentation of patients with status epilepticus categorized by type of hospital discharge

\begin{tabular}{|c|c|c|c|}
\hline Factors & Good outcome & Poor outcome & $P$-value \\
\hline & & & \\
\hline Body temperature, ${ }^{\circ} \mathrm{C}$ & $37.22(1.01)$ & $37.42(1.26)$ & 0.219 \\
\hline Systolic blood pressure, $\mathrm{mmHg}$ & | $38.22(28.4 \mid)$ & | 38.24 (32.72) & 0.996 \\
\hline Pulse rate, bpm & $98.42(23.40)$ & $102.44(24.75)$ & 0.249 \\
\hline Glasgow coma scale & $9.78(3.5 \mathrm{I})$ & $7.97(4.01)$ & $<0.001$ \\
\hline Endotracheal intubation, n (\%) & $67(58.26)$ & $58(65.17)$ & 0.315 \\
\hline \multicolumn{4}{|l|}{ Laboratory results } \\
\hline Hematocrit, \% & $26.04(17.53)$ & $23.83(17.76)$ & 0.367 \\
\hline White blood cell count, cells $/ \mathrm{mm}^{3}$ & $8,492.60(6,724.24)$ & $8,4 I I .43(7,789.93)$ & 0.936 \\
\hline Plasma glucose, $\mathrm{mg} / \mathrm{dL}$ & $159.26(84.18)$ & $203.11(121.93)$ & 0.006 \\
\hline Blood urea nitrogen, $\mathrm{mg} / \mathrm{dL}$ & I3.32 (I0.69) & $31.09(36.64)$ & $<0.001$ \\
\hline Creatinine, $\mathrm{mg} / \mathrm{dL}$ & $1.18(1.26)$ & $2.01(1.88)$ & $<0.001$ \\
\hline Serum sodium, mEq/L & I35.49 (8.03) & I38.03 (6.57) & 0.034 \\
\hline Serum potassium, mEq/L & $3.57(0.89)$ & $3.70(0.77)$ & 0.318 \\
\hline Serum chloride, $\mathrm{mEq} / \mathrm{L}$ & $99.27(9.09)$ & $103.30(7.27)$ & 0.006 \\
\hline Serum bicarbonate, $\mathrm{mEq} / \mathrm{L}$ & $22.37(4.8 I)$ & $20.03(5.82)$ & 0.007 \\
\hline Serum calcium, mg/dL & $8.44(0.88)$ & $8.30(1.38)$ & 0.532 \\
\hline Serum phosphate, $\mathrm{mg} / \mathrm{dL}$ & $3.02(1.12)$ & $3.79(2.27)$ & 0.037 \\
\hline Total cholesterol, mg/dL & $168.08(49.37)$ & I58.87 (57.92) & 0.555 \\
\hline Serum albumin, g/dL & $3.52(0.66)$ & $2.73(0.93)$ & $<0.00$ I \\
\hline Serum ALT, U/L & $533.67(61.28)$ & I 47.63 (275.02) & 0.052 \\
\hline Serum AST, U/L & $82.78(102.35)$ & I7I.36 (205.69) & 0.031 \\
\hline Total bilirubin, mg/dL & $1.04(0.79)$ & $\mathrm{I} .84(\mathrm{I} .49)$ & 0.017 \\
\hline Alkaline phosphatase, $\mathrm{mg} / \mathrm{dL}$ & |II.3I (8I.39) & $106.89(88.13)$ & 0.857 \\
\hline
\end{tabular}

Note: Data presented as mean (standard deviation) unless indicated otherwise.

Abbreviations: ALT, alanine aminotransferase; AST, aspartate aminotransferase. 
Table 4 Treatment and treatment outcomes of patients with SE categorized by type of hospital discharge

\begin{tabular}{|c|c|c|c|}
\hline Factors & $\begin{array}{l}\text { Good outcome } \\
N=\mid 20\end{array}$ & $\begin{array}{l}\text { Poor outcome } \\
\mathrm{N}=9 \text { | }\end{array}$ & $P$-value \\
\hline SE time prior to treatment, minutes & $150.83(257.64)$ & $159.19(344.43)$ & 0.848 \\
\hline SE treatment time to control SE, minutes & $88.81(175.08)$ & $191.47(621.38)$ & 0.143 \\
\hline Total SE time, minutes & $225.77(268.90)$ & $360.09(723.49)$ & 0.108 \\
\hline Recurrent SE, n (\%) & $13(10.83)$ & $39(42.86)$ & $<0.001$ \\
\hline Interictal time, hours & $5.54(12.24)$ & $1.16(6.59)$ & 0.001 \\
\hline Numbers of AED use & $2.55(I .7 I)$ & $2.44(1.35)$ & 0.612 \\
\hline \multicolumn{4}{|l|}{ Types of AED use } \\
\hline \multicolumn{4}{|l|}{ Primary AED } \\
\hline Diazepam, n (\%) & 91 (75.83) & $69(75.82)$ & 0.747 \\
\hline Phenytoin, n (\%) & $26(21.67)$ & $21(23.08)$ & 0.747 \\
\hline Sodium valproate, $n(\%)$ & $3(2.50)$ & I (I.I0) & 0.747 \\
\hline \multicolumn{4}{|l|}{ Secondary AED } \\
\hline Phenytoin, n (\%) & 91 (98.91) & $77(100)$ & 0.359 \\
\hline Sodium valproate, $\mathrm{n}(\%)$ & I (I.09) & 0 & 0.359 \\
\hline \multicolumn{4}{|l|}{ Others } \\
\hline Midazolam, n (\%) & 0 & $3(0.03)$ & 0.079 \\
\hline Propofol, n (\%) & 0 & $2(0.02)$ & 0.185 \\
\hline Length of hospital stay, days & $4.69(6.12)$ & $5.69(7.50)$ & 0.287 \\
\hline Duration of respirator use, days & $1.83(3.92)$ & $4.18(6.21)$ & $<0.001$ \\
\hline Aspirated pneumonia, $\mathrm{n}(\%)$ & $33(27.50)$ & $20(21.98)$ & 0.360 \\
\hline
\end{tabular}

Note: Data presented as mean (standard deviation) unless indicated otherwise.

Abbreviations: AED, antiepileptic drug; SE, status epilepticus.

plasma glucose levels. An increase of $1 \mathrm{mg} / \mathrm{dL}$ of plasma glucose increased the risk of having poor discharge status by $1.2 \%$.

A previous study from Singapore also showed that in SE patients with a hyperglycemia equal to or more than $7 \mathrm{mmol} / \mathrm{L}(126 \mathrm{mg} / \mathrm{dL})$, these levels were associated with poor outcomes of SE. ${ }^{8}$ In animal models, hyperglycemia causes hippocampal damage and also aggravates seizures..$^{9,10}$ Therefore, glucose control may be important in SE patients, particularly in Asian populations. These results may not apply to Western populations. Two studies from Switzerland did not have findings similar to this study. ${ }^{11,12}$ Hyperglycemia was, however, shown to be associated with poor outcome in acute ischemic stroke. ${ }^{13}$

Some factors such as serum albumin or aspartate aminotransferase were significantly different between the good and poor SE outcomes by univariate logistic analysis or descriptive statistics. Both factors, however, were not statistically significant in the multivariate logistic regression analysis. These results implied that only plasma glucose was an independent factor or predictor for SE outcome.

The population of this study may be different from other previous studies in terms of causes of SE. In the current study, acute stroke, alcohol related causes, and septic encephalopathy accounted for $41.23 \%$ of the entire subjects. Unlike in Western populations, AED withdrawal was found only in $9 \%$. The previous study from Thailand found that the mortality rate of SE was $35 \%,{ }^{2}$ while refractory SE may have a mortality rate of $50 \%{ }^{14,15}$ The poor outcome rate of this study was $43.13 \%$. The poor discharge statuses were one of the following: death; not improved or discharged against advice; or presence of a neurological deficit.

The strengths of this study were the quite-large sample size and different causes of SE as compared with previous studies. ${ }^{11,12}$ There are some limitations. Retrospective data collection may not have complete data, particularly laboratory findings such as $\mathrm{HbA}_{1 \mathrm{c}}$ levels or history of previous medications that may affect plasma glucose levels such as steroid use. Also noted was that the population in this study was mostly not refractory SE; only three and two patients had received midazolam and propofol, respectively. Further studies are needed particularly in refractory SE. The results of this study may apply only to Asian populations or other countries in Southeast Asia.

\section{Conclusion}

Initial plasma glucose is associated with poor discharge status in patients with $\mathrm{SE}$.

\section{Acknowledgments}

This study was supported by TRF grants from Senior Research Scholar Grant, Thailand Research Fund grant number 
RTA5580004 and the Higher Education Research Promotion and National Research University Project of Thailand, Office of the Higher Education Commission, Thailand through the Health Cluster (SHeP-GMS), Khon Kaen University. The authors also would like to thank Dr Thanachai Panaput for his kind advice on statistical analyses, Ms Kanokwan Boonpracheon (medical student) for her assistance in data management, and Professor James A Will (University of Wisconsin, Madison, WI, USA) for review of the manuscript.

\section{Disclosure}

The authors report no conflicts of interest in this work.

\section{References}

1. Brophy GM, Bell R, Claassen J, et al. Guideline for the evaluation and management of status epilepticus. Neurocrit Care. 2012;17(1):3-23.

2. Tiamkao S, Suko P, Mayurasakorn N; Srinagarind Epilepsy Research Group. Outcome of status epilepticus in Srinagarind Hospital. J Med Assoc Thai. 2010;93(4):420-423.

3. Tiamkao S, Pranbul S, Sawanyawisuth K, Thepsuthammarat K; Integrated Epilepsy Research Group. A national database of incidence and treatment outcomes of status epilepticus in Thailand. Int J Neurosci. 2014; 124(6):416-420.

4. Tsai MH, Chuang YC, Chang HW, et al. Factors predictive of outcome in patients with de novo status epilepticus. QJM. 2009;102(1):57-62.
5. Aminoff MJ, Simon RP. Status epilepticus. Causes, clinical features and consequences in 98 patients. Am J Med. 1980;69(5):657-666.

6. Neligan A, Shorvon SD. Prognostic factors, morbidity and mortality in tonic-clonic status epilepticus: a review. Epilepsy Res. 2011;93(1):1-10.

7. Neligan A, Shorvon SD. Frequency and prognosis of convulsive status epilepticus of different causes: a systematic review. Arch Neurol. 2010; 67(8):931-940.

8. Rathakrishnan R, Sidik NP, Huak CY, Wilder-Smith EP. Generalised convulsive status epilepticus in Singapore: clinical outcomes and potential prognostic markers. Seizure. 2009;18(3):202-205.

9. Huang CW, Cheng JT, Tsai JJ, Wu SN, Huang CC. Diabetic hyperglycemia aggravates seizures and status epilepticus-induced hippocampal damage. Neurotox Res. 2009;15(1):71-81.

10. Schauwecker PE. The effects of glycemic control on seizures and seizure-induced excitotoxic cell death. BMC Neurosci. 2012;13:94

11. Alvarez V, Januel JM, Burnand B, Rossetti AO. Role of comorbidities in outcome prediction after status epilepticus. Epilepsia. 2012;53(5): e89-e92.

12. Rossetti AO, Alvarez V, Januel JM, Burnand B. Treatment deviating from guidelines does not influence status epilepticus prognosis. J Neurol. 2013;260(2):421-428.

13. Stead LG, Gilmore RM, Bellolio MF, et al. Hyperglycemia as an independent predictor of worse outcome in non-diabetic patients presenting with acute ischemic stroke. Neurocrit Care. 2009;10(2):181-186.

14. Cooper AD, Britton JW, Rabinstein AA. Functional and cognitive outcome in prolonged refractory status epilepticus. Arch Neurol. 2009; 66(12):1505-1509.

15. Sutter R, Marsch S, Fuhr P, Rüegg S. Mortality and recovery from refractory status epilepticus in the intensive care unit: a 7-year observational study. Epilepsia. 2013;54(3):502-511.
Neuropsychiatric Disease and Treatment

\section{Publish your work in this journal}

Neuropsychiatric Disease and Treatment is an international, peerreviewed journal of clinical therapeutics and pharmacology focusing on concise rapid reporting of clinical or pre-clinical studies on a range of neuropsychiatric and neurological disorders. This journal is indexed on PubMed Central, the 'PsycINFO' database and CAS,

\section{Dovepress}

and is the official journal of The International Neuropsychiatric Association (INA). The manuscript management system is completely online and includes a very quick and fair peer-review system, which is all easy to use. Visit http://www.dovepress.com/testimonials.php to read real quotes from published authors. 